\title{
Novel Double Central Ray Amputation of the Third and Fourth Digits: Case Report and Literature Review
}

\author{
Mohamad K. Abou Chaar ${ }^{c}$ Omar I. Jaber ${ }^{b}$ Wafa Ashad Samer Abdel Ala \\ aDepartment of Orthopedic Oncology, King Hussein Cancer Center, Amman, Jordan; \\ ${ }^{b}$ Department of Pathology and Laboratory Medicine, King Hussein Cancer Center, Amman, \\ Jordan; 'Department of Surgery, King Hussein Cancer Center, Amman, Jordan; dDepartment \\ of Radiation Oncology, King Hussein Cancer Center, Amman, Jordan
}

Keywords

Cancer · Double ray amputation · Hand surgery · Orthopedic · Soft tissue sarcoma · Tumor

\begin{abstract}
Whenever partial hand amputations for soft tissue sarcomas are attempted, special consideration should be given to achieve a balance between complete resection associated with negative margins and preservation of functionality to the patient so that the hand can support the contralateral intact hand for bimanual activities. This difficult decision is even more challenging within the limited anatomical confines of the hand. Based on our literature review, this is the first case of double central 3rd and 4th ray amputation, as far as we know with good hand function, evaluated by the Musculoskeletal Tumor Rating Scale.
\end{abstract}

\section{Introduction}

Osteosarcomas and many soft tissue sarcomas (STS) occur in the extremities, most of which are treated with a combination of a wide local excision, radiotherapy, and reconstruction. However, sometimes STS necessitate amputation [1, 2]. Ray amputation was first described in the early 20th century [3-6], and it was performed on those with proximal interphalangeal joint dysfunction or loss of proximal phalangeal skeleton; it was also used for the treatment of traumatic hand injuries, infections, and tumors [7]. 
Fig. 1. MRI of the right hand. T1 axial cut showing the tumor mainly in the dorsal space between the 3rd and 4th metacarpophalangeal (MCP) joint (red arrowhead) extending to the volar aspect through the intrinsic muscles of the related MCP, as well as its invasion of the tendon and part of the periosteum of the dorsoulnar aspect of the 3rd MCP joint.

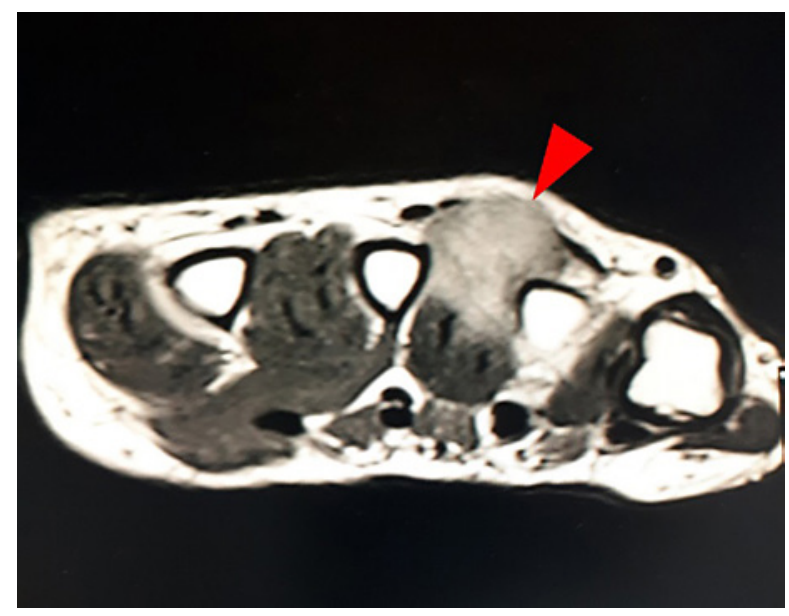

We present the case of a 38-year-old male patient with a tumor located in between the 3rd and the 4th metacarpophalangeal joint that had been incompletely excised outside our facility using both a volar and a dorsal approach with subsequent positive margins, so he underwent novel central double 3rd and 4th ray amputation due to the contaminated surgical tumor bed. Based on our literature review, this is the first case of double central 3rd and 4th ray amputation, as far as we know with good hand function, assessed by the Musculoskeletal Tumor Rating Scale (MSTS).

\section{Case Report}

We describe the case of a 38-year-old right-handed male nonsmoking computer technician who was known to have dilated cardiomyopathy. He noticed a soft lump around the right 4th metacarpophalangeal joint measuring $1.5 \times 1.5 \mathrm{~cm}$. The lump had been present for almost 1 year and had started to become painful, hard, and increasing in size in the last couple of months. The patient underwent magnetic resonance imaging (MRI), which showed evidence of tumor depicted on the dorsal subcutaneous aspect of the hand at the level of the 3rd and 4 th metacarpal head digits measuring $2.4 \times 2.1 \mathrm{~cm}$ in axial dimension and $3.7 \mathrm{~cm}$ in craniocaudal dimension, with volar extension to invade the muscles surrounding the 4th metacarpophalangeal joint, in close relation with the cortex of the 4th metacarpal bone and the proximal phalanx without definite invasion (Fig. 1). It was reported that no signs of metastatic disease were found. A biopsy was done, which showed clear cell sarcoma, melanoma of the soft part, grade 2 . The patient underwent incomplete excision outside our center, and the tumor was removed using a double incision (volar and dorsal approach).

Upon his initial visit to our facility, the anterior and posterior incisions were completely healed and a drop in the ring finger was noted due to loss of extensor tendon, which was involved by the tumor as well. The specimen was reviewed and showed multiple peripheral and volar margins involved by the tumor. MRI of the right hand showed evidence of an illdefined infiltrative soft tissue enhancement between the 3rd and 4th metacarpal bones extending through the metacarpophalangeal joint distally, but no definable well-defined nodules or masses. The enhancement was reaching the surrounding major tendons. Whole body positron emission tomography-computed tomography and brain MRI showed no evidence of metastatic disease. The multidisciplinary clinical decision was to proceed with 3 rd and 4 th ray amputation. It should be noted that considerable time was spent explaining 


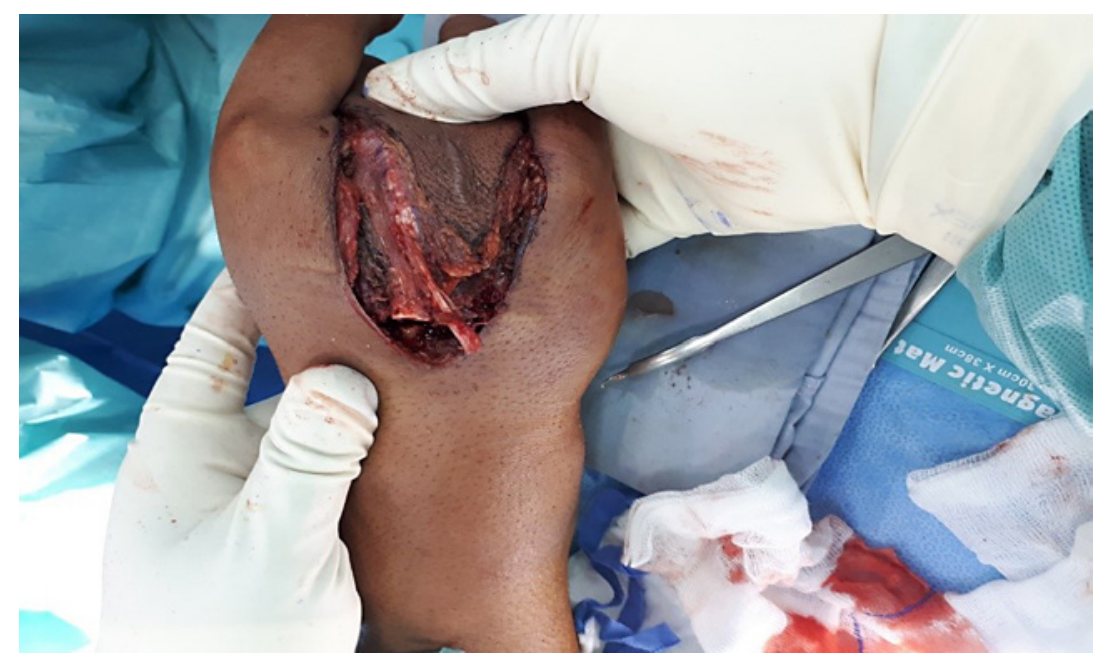

Fig. 2. Dorsal approach making a V-shaped incision exposing the subcutaneous tissue, extensor tendon, and periosteum.

the operation to the patient, with all possible complications including skin necrosis due to low vascularity, infection at the operation site, major hand dysfunction, and local tumor recurrence.

Under a bloodless field without exsanguination, we performed a V-shaped incision incorporating both the dorsal and the volar incisions that had been conducted previously and which had resulted in contamination of the field. A dorsal approach was utilized first, where we went through the layers (skin, subcutaneous tissue, extensor tendon, and periosteum) till the apex of our V-shaped incision proximally (Fig. 2). We sent tissue samples for frozen sections from both proximal and distal aspects as well as both radial and ulnar areas to check our margins. A considerable amount of time was spent identifying any abnormal tissue around the site of dissection till we reached the base of the 3rd and 4th metacarpal bones and did our osteotomy there. We turned our attention to the $\mathrm{V}$ shape of the volar aspect and continued our dissection in layers while carefully inspecting any abnormal tissue and avoiding any violation of the residual tumor area (Fig. 3). Carefully, we identified both common digital nerves and arteries, and we cut only branches supplying the $3 \mathrm{rd}$ and 4 th digits while preserving the other digits' important neurovascular structures; again, tissue samples were sent for freezing, including the volar ligament plates. After that, the residual area was completely removed by en bloc excision (Fig. 4) and sent for permanent pathology, which turned out to be completely excised with negative margins all around. We elected to close the wound by primarily using the aid of the volar ligament plates, then inserting a drain, and we ensured adequate hemostasis (Fig. 5). The wound's edges came nicely together and sterile dressing was applied.

The patient was discharged from our facility 3 days after the procedure. His first followup visit was after 8 days, on which he showed a well-healed incision site. He was scheduled for regular appointments with physiotherapy. Three months after the operation, follow-up MRI was done; there were only ill-defined edematous soft tissue changes but no definable enhancing soft tissue masses. The most recent MRI showed no definable enhancing soft tissue mass at the surgical tumor bed that would account for local tumor recurrence. The patient was followed up for 2 years with no sign of local recurrence or metastasis. 

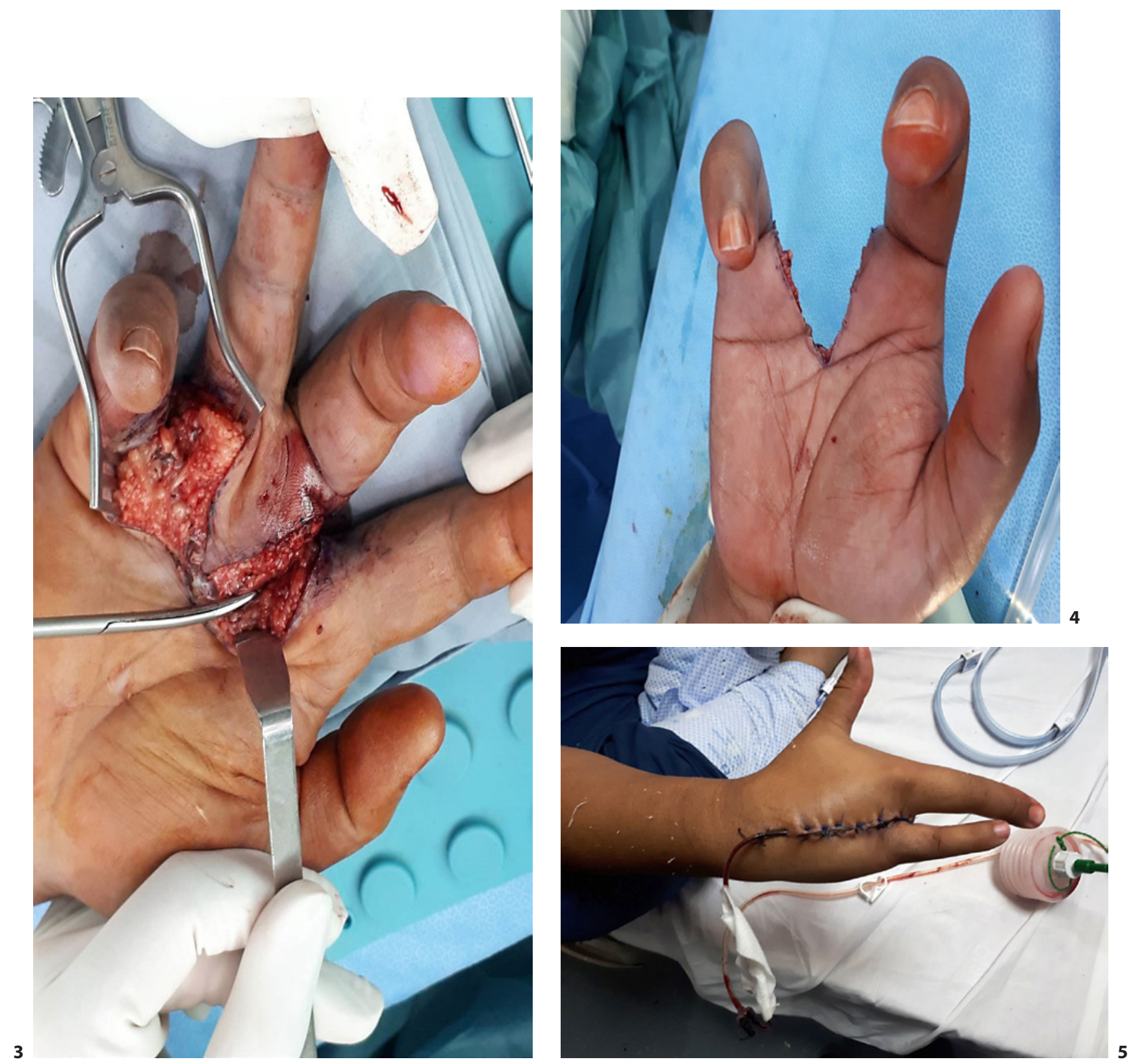

Fig. 3. V-shaped incision into the volar aspect of the right hand.

Fig. 4. Complete en bloc resection of the tumor bed with the 3rd and 4th digits.

Fig. 5. Primary closure using ligament plates after inserting a negative-pressure drain.

\section{Discussion}

Hand preservation surgery is possible for most patients with malignant tumors of the hand [8-10]. Sarcomas, on the other hand, are a rare and heterogeneous group of malignant tumors of mesenchymal origin that comprise less than $1 \%$ of all adult malignancies and $12 \%$ of pediatric cancers [11-13]. Approximately $80 \%$ of new cases of sarcoma originate from soft tissue, and the rest originate from bone [13]. Clear cell sarcoma, previously known as melanoma of the soft parts, is a malignant soft tissue tumor with melanocytic differentiation. 


\section{Case Reports in \\ Oncology}

\begin{tabular}{l|l}
\hline Case Rep Oncol 2020;13:91-99 \\
\hline DOI: 10.1159/000504934 & $\begin{array}{l}\text { @ 2020 The Author(s). Published by S. Karger AG, Basel } \\
\text { www.karger.com/cro }\end{array}$ \\
\hline
\end{tabular}

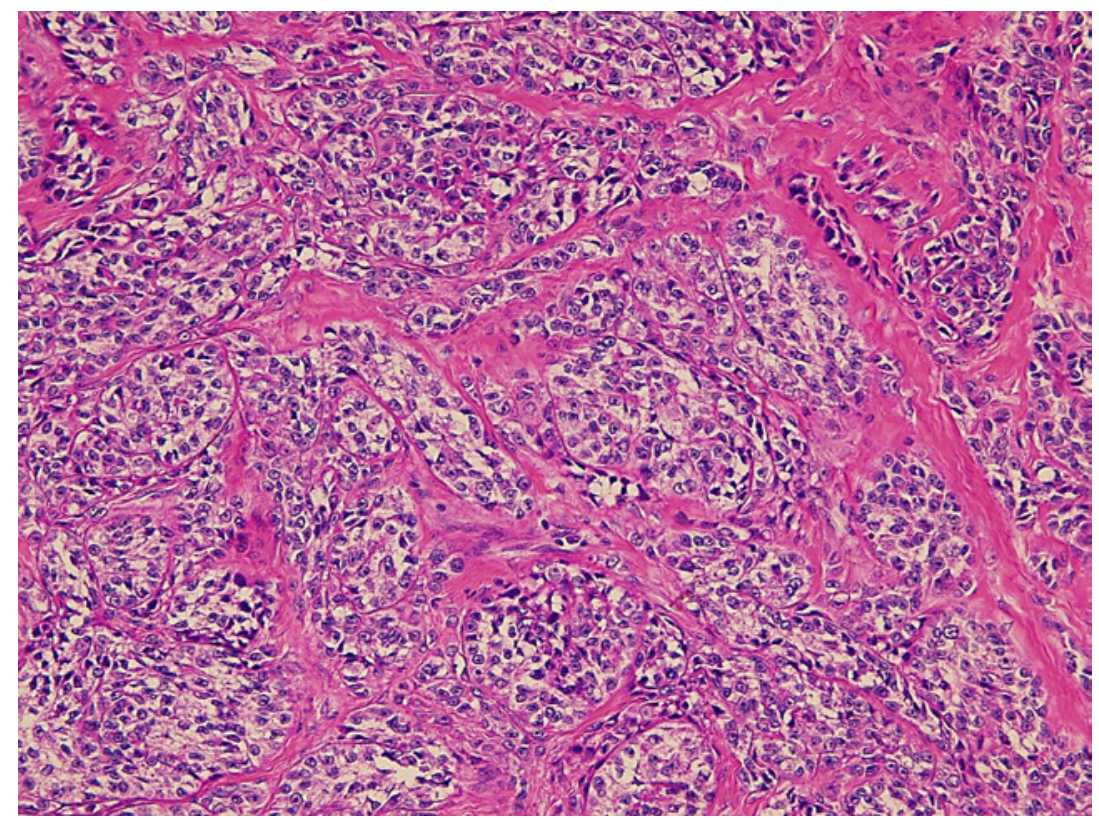

Fig. 6. Clear cell sarcoma. The tumor is composed of nests of uniform spindle-shaped-to-epithelioid cells with clear cytoplasm, round nuclei, and prominent nucleoli. Notice the dense fibrotic background. Hematoxylin and eosin. $\times 200$.

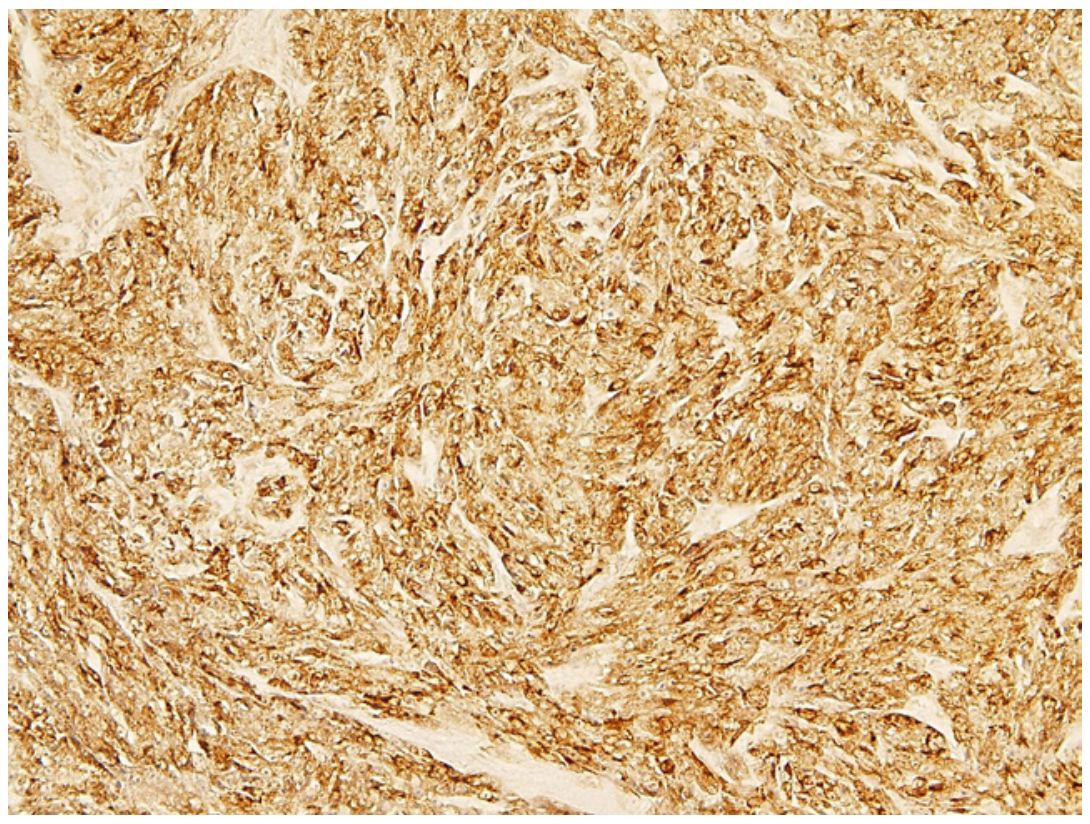

Fig. 7. HMB-45 immunohistochemical stain in clear cell sarcoma. Notice the strong and diffuse pattern of staining. HMB-45 immunohistochemical stain. $\times 200$. 


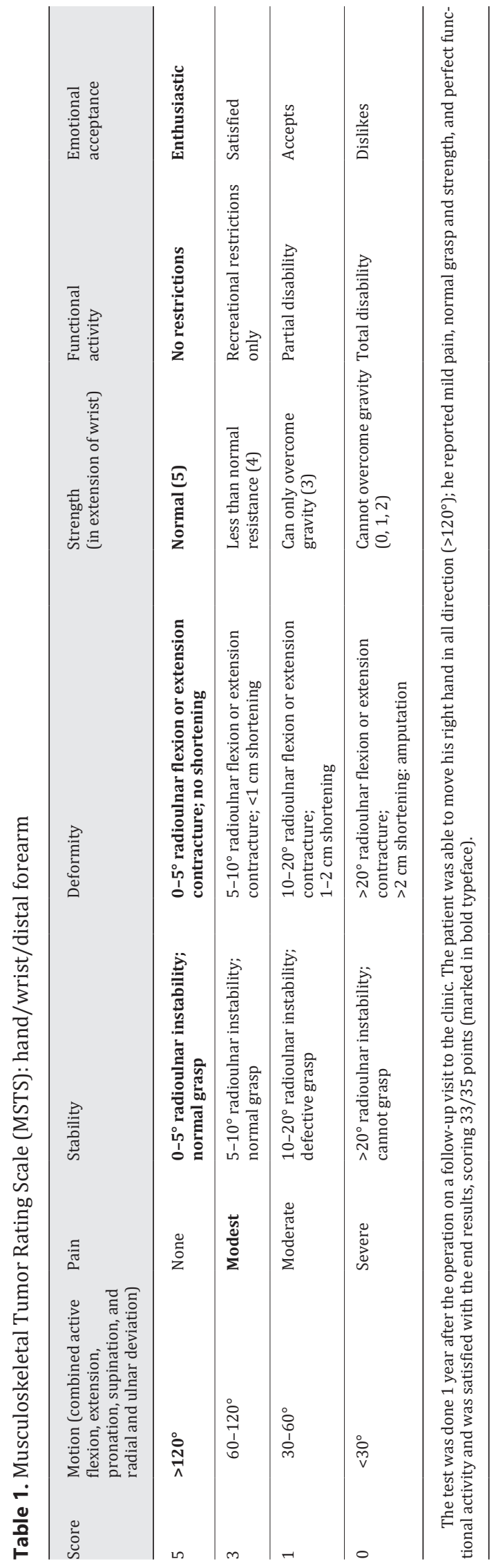




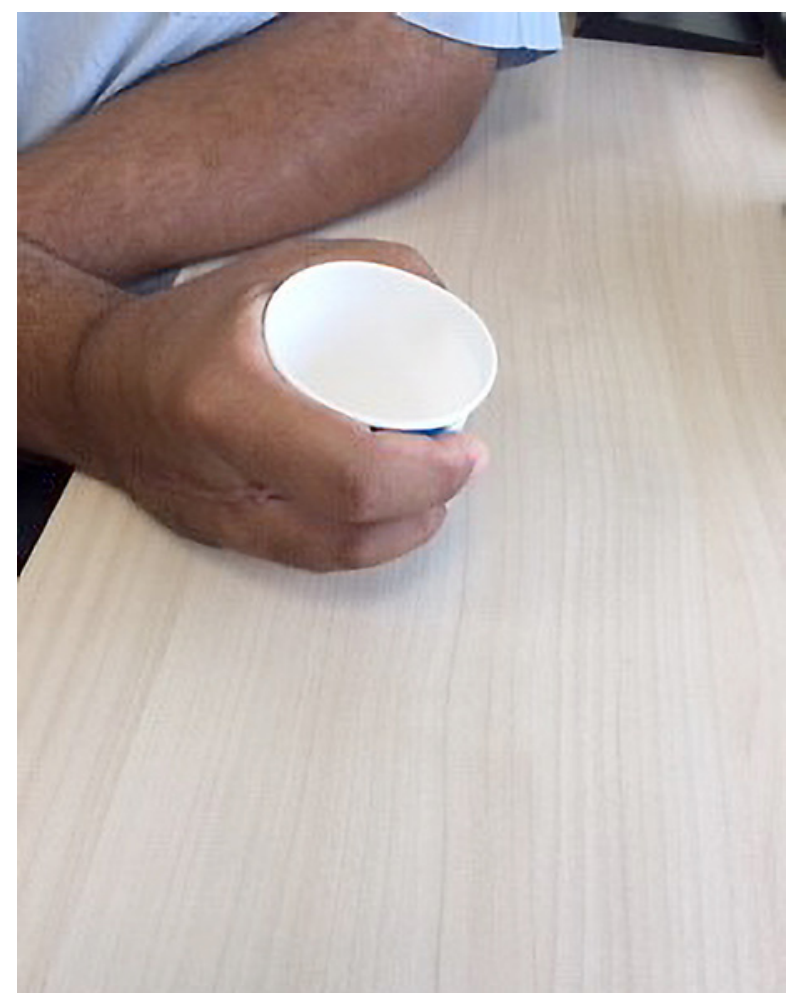

Fig. 8. The patient is able to hold and manipulate objects of varying sizes in his hand and he can write (not shown).

It mostly occurs in the distal extremities around the ankle or foot, followed by locations around the wrist and hands. Grossly, it has infiltrative borders mostly associated with the tendons or aponeuroses. Histologically, the tumor is composed of nests or bundles of uniform, spindle-shaped-to-epithelioid cells on a background of dense fibrous septa (Fig. 6). The cells contain moderate amounts of eosinophilic-to-clear cytoplasm, with central nuclei and large prominent single nucleoli. In some cases, melanin pigments can be identified. The mitotic rate is low and pleomorphism is not seen, in contrast to melanoma, where pleomorphism is often prominent. On immunohistochemistry, clear cell sarcoma has staining patterns similar to those of melanoma: both tumors are positive for S100 protein, HMB-45 (Fig. 7), microphthalmia-associated transcription factor, and melan A. In contrast to melanoma, the HMB-45 staining pattern is stronger and more diffuse compared to that of $\mathrm{S} 100$ protein. In addition, clear cell sarcoma is characterized by a reciprocal translocation $t(12 ; 22)(q 13 ; q 12)$ [14] resulting in EWSR1-ATF1 oncogene fusion [15] Therefore, detecting this gene rearrangement by FISH, PCR, or next-generation sequencing is helpful for confirming the diagnosis in challenging cases, especially when the differential diagnosis is malignant melanoma.

In treating clear cell sarcoma, the major therapeutic goals are survival, avoidance of recurrence, maximizing function, and minimizing morbidity. Surgical resection is the standard primary treatment for most patients with clear cell sarcoma, although close margins may be necessary to preserve uninvolved critical neurovascular structures. Radiotherapy and/or chemotherapy are often used prior to surgery in many centers to downstage large high-grade tumors to enable effective surgical resection with close soft tissue margins $(<1 \mathrm{~cm})$ or a microscopically positive margin on bone, major blood vessels, or a nerve, but unfortunately clear cell sarcoma is not sensitive to cytotoxic chemotherapy [16]. Studies have demonstrated 
that it is possible to perform en bloc resection of STS of the hand with good oncologic outcomes while preserving a functional hand $[8,17]$. However, the limited anatomical confines of the hand make achieving negative surgical margins difficult, but ultimately necessary to achieve a better clinical outcome [18]. Puhaindran and Athanasian [16] reported 5 cases of double ray amputation ( 4 cases of 4 th and 5 th ray amputation, and 1 case of 2 nd and 3rd ray amputation) with lower MSTS scores (24 vs. 27.5) than in single ray amputation cases. Another case was reported by Fleegler [17], i.e., a 42-year-old woman who was diagnosed with synovial sarcoma and underwent double 2nd and 3rd ray amputation; however, the author did not provide any information regarding the functionality of the affected hand.

In the case we presented, our patient underwent central double 3rd and 4th ray amputation and was able to maintain an almost normal function of the affected hand, as he scored 33/35 (Table 1) on the MSTS [18]. This was a good result, since the procedure might cause contracture and fibrosis [19-22], which will lower the MSTS score, as described by Puhaindran and Athanasian [16], who reported 4 cases with a mean score of 23.5. Our patient indicated that his work required a lot of precision and he did not lose any of his skills (Fig. 8). It should be noted that the functionality of the hand and esthetic outcome after partial hand amputation depend on the extent of the digits excised and the patient's adherence to physiotherapy.

\section{Statement of Ethics}

We have obtained written informed consent from the patient to publish this report.

\section{Disclosure Statement}

The authors have nothing to disclose.

\section{Author Contributions}

M.K.A.C. and W.A. performed the literature search, guided by S.A.A, and wrote the manuscript. O.I.J. obtained and reviewed the pathology samples and provided the images with a legend from a pathological point of view. S.A.A. oversaw the inception of the case report, guided the literature search, counseled the patient, wrote the part on surgical technique and

\section{References}

Clark MA, Thomas JM. Amputation for soft-tissue sarcoma. Lancet Oncol. 2003 Jun;4(6):335-42.

2 Veth R, van Hoesel R, Pruszczynski M, Hoogenhout J, Schreuder B, Wobbes T. Limb salvage in musculoskeletal oncology. Lancet Oncol. 2003 Jun;4(6):343-50.

3 Bunnell S. Physiological reconstruction of a thumb after total loss. Surg Gynecol Obstet. 1931;52:245-8.

4 Bunnell S. Reconstructive surgery of the hand. Surg Gynecol Obstet. 1924;39:259-74.

5 Colen L, Bunkis J, Gordon L, Walton R. Functional assessment of ray transfer for central digital loss. J Hand Surg Am. 1985 Mar;10(2):232-7.

6 Fleishman EA. Dimensional analysis of psychomotor abilities. J Exp Psychol. 1954 Dec;48(6):437-54.

7 Slocum DB. Amputations of the fingers and the hand. Clin Orthop. 1959;15:35-59.

8 Miller RW, Young JL Jr, Novakovic B. Childhood cancer. Cancer. 1995 Jan;75(1 Suppl):395-405.

9 Jo VY, Fletcher CD. WHO classification of soft tissue tumours: an update based on the 2013 (4th) edition. Pathology. 2014 Feb;46(2):95-104.

10 Siegel RL, Miller KD, Jemal A. Cancer statistics, 2019. CA Cancer J Clin. 2019 Jan;69(1):7-34.

11 Stenman G, Kindblom LG, Angervall L. Reciprocal translocation t(12;22)(q13;q13) in clear-cell sarcoma of tendons and aponeuroses. Genes Chromosomes Cancer. 1992 Mar;4(2):122-7. 
12 Zucman J, Delattre O, Desmaze C, Epstein AL, Stenman G, Speleman F, et al. EWS and ATF-1 gene fusion induced by $\mathrm{t}(12 ; 22)$ translocation in malignant melanoma of soft parts. Nat Genet. 1993 Aug;4(4):341-5.

13 National Comprehensive Cancer Network. Soft tissue sarcoma (2.2019) [Internet] [accessed 2019 May 17]. http://www.nccn.org/professionals/physician_gls/pdf/sarcoma.pdf.

14 Bray PW, Bell RS, Bowen CV, Davis A, O'Sullivan B. Limb salvage surgery and adjuvant radiotherapy for soft tissue sarcomas of the forearm and hand. J Hand Surg Am. 1997 May;22(3):495-503.

15 Owens JC, Shiu MH, Smith R, Hajdu SI. Soft tissue sarcomas of the hand and foot. Cancer. 1985 May 1;55(9): 2010-8.

16 Puhaindran ME, Athanasian EA. Malignant and metastatic tumors of the hand. J Hand Surg Am. 2010 Nov; 35(11):1895-900; quiz 1900.

17 Fleegler EJ. An approach to soft tissue sarcomas of the hand and upper limb. J Hand Surg Br. 1994 Aug;19(4): 411-9.

18 Enneking WF, Dunham W, Gebhardt MC, Malawar M, Pritchard DJ. A system for the functional evaluation of reconstructive procedures after surgical treatment of tumors of the musculoskeletal system. Clin Orthop Relat Res. 1993 Jan;(286):241-6.

19 Brien EW, Terek RM, Geer RJ, Caldwell G, Brennan MF, Healey JH. Treatment of soft-tissue sarcomas of the hand. J Bone Joint Surg Am. 1995 Apr;77(4):564-71.

20 Buecker PJ, Villafuerte JE, Hornicek FJ, Gebhardt MC, Mankin HJ. Improved survival for sarcomas of the wrist and hand. J Hand Surg Am. 2006 Mar;31(3):452-5.

21 Macià I Garau M, Calduch AL, López EC. Radiobiology of the acute radiation syndrome. Rep Pract Oncol Radiother. 2011 Jul;16(4):123-30.

22 Stubblefield MD. Radiation fibrosis syndrome: neuromuscular and musculoskeletal complications in cancer survivors. PM R 2011 Nov;3(11):1041-54. 